\title{
RARy-induced E-cadherin downregulation promotes hepatocellular carcinoma invasion and metastasis
}

Wen-Juan Gan ${ }^{1,2+}{ }^{2}$, Jing-Ru Wang ${ }^{1+}$, Xiao-Li Zhu ${ }^{2+},{ }^{+}$Xiao-Shun He${ }^{2}$, Peng-Da Guo ${ }^{1}$, Shen Zhang ${ }^{1}$, Xiu-Ming Li ${ }^{1}$, Jian-Ming $\mathrm{Li}^{1 *}$ and Hua Wu${ }^{1 *}$

\begin{abstract}
Background: Aberrant expression of Retinoic acid receptor $\gamma$ (RARY) is implicated in cancer development. Our previous study identified that RARY functions as a tumor promoter to drive hepatocellular carcinoma (HCC) growth. However, its contribution to HCC invasion and metastasis remains unclear.

Methods: RARy expression in clinical HCC samples was detected by western blot and immunohistochemistry. The relationship between RARy expression levels and the clinical characteristics were evaluated. HCC cell line MHCC-97H were stably knocked down RARy using a lentivirus vector-based shRNA technique. The cells were analyzed by migration and invasion assays, and injected into nude mice to assess tumor metastasis. E-cadherin expression regulated by RARy was examined by qPCR, western blot and immunofluorescence staining.

Results: The expression of RARY is significantly upregulated in human HCC tissues. Moreover, its expression positively correlates with tumor size, distant metastasis and TNM stage, and negatively correlates with length of survival of HCC patients. Knockdown of RARy markedly inhibits HCC cell invasion and metastasis both in vitro and in vivo. Mechanistic investigations reveal that RARY functions through regulation of NF-KB-mediated E-cadherin downregulation to promote HCC invasion and metastasis. Notably, RARY expression status negatively correlates with E-cadherin expression in HCC cell lines and clinical HCC samples.

Conclusions: These findings demonstrate that RARY could promote HCC invasion and metastasis by regulating E-cadherin reduction, and implicate new strategies to aggressively treat HCC through targeting RARY/E-cadherin signaling axis.
\end{abstract}

Keywords: RARY, E-cadherin, Hepatocellular carcinoma, Metastasis

\section{Background}

Hepatocellular carcinoma (HCC) is one of the most common cancer types worldwide, particularly in China $[1,2]$. HCCs that undergo early vascular invasion are highly resistant to existing therapies, such as chemotherapy [3]. Although current advances have been made in the diagnosis of $\mathrm{HCC}$, the overall survival rate of the HCC patients is disappointingly low due to recurrence and metastasis $[4,5]$. Extensive studies have identified

\footnotetext{
* Correspondence: jianmingli@suda.edu.cn; wuhua@suda.edu.cn

${ }^{\dagger}$ Equal contributors

${ }^{1}$ Pathology Center and Department of Pathology, Soochow University,

Suzhou 215123, China

Full list of author information is available at the end of the article
}

that many risk factors such as hepatitis B (HBV) and hepatitis $\mathrm{C}(\mathrm{HCV})$, and dysregulation of signaling pathway and molecules, are implicated in HCC development $[6,7]$. However, little is known about how HCC undergoes metastasis. Therefore, identifying potential molecular mechanisms contributing to the metastasis of $\mathrm{HCC}$ is one of the most critical issues.

Metastasis, a complex biological process that involves tumor cells detaching from the primary tumor, migrating and locating in distant organs, is the principal cause leading to death in all types of cancer including HCC $[8,9]$. Significant advances have been made in understanding the molecular mechanisms underlying metastasis, and several signalings and molecules have been 
identified [10]. Accumulating evidence indicates that epithelial-mesenchymal transition (EMT) is a crucial step for cancer cell invasion and metastasis initiation [11]. Downregulation of E-cadherin, a single-span transmembrane glycoprotein located primarily within adherent junction, is a fundamental feature of EMT [8, 12-14]. Loss of E-cadherin correlates with poorer survival for patients with numerous cancers such as gastric cancer and HCC $[15,16]$. Loss or reduction of E-cadherin expression in human tumors can be caused by somatic mutations, chromosomal deletions, DNA methylation and several intracellular EMT-inducers like Twist, Snail, Slug, Zeb1, Zeb2 and others [17-26]. For example, somatic point mutations of the E-cadherin gene [17] and/or promoter methylation lead to E-cadherin loss [20, 27], and the loss of E-cadherin expression is considered to be a distinguishing feature in both lobular breast cancer and diffuse gastric cancer [27, 28]. Transcriptional repressors, such as Snail, Slug and Twist, directly bind to the E-cadherin promoter to transcriptionally repress E-cadherin expression in breast cancer [22, 29]. We recently also reported that Nur77, an orphan member of the nuclear receptor superfamily, induces E-cadherin reduction in a Matrix metalloproteinase 9 (MMP-9)-dependent manner, and subsequently contributes to the invasion and metastasis of colorectal cancer [8]. Despite these efforts to understand the molecular mechanism of E-cadherin ablation or reduction in cancer, however, regulation of E-cadherin expression in cancer is still poorly understood.

Retinoic acid receptor $\gamma$ (RAR $\gamma$ ) is a member of the nuclear receptor subfamily. Recent studies implicate RAR $\gamma$ in cancer development and progression. A lot of efforts have been made to explore the regulatory mechanism of RAR $\gamma$ in cancer, but there are contradictory views regarding its role in cancer. On one hand, RARy may function as an oncogene to drive cancer cell growth and metastasis. For example, RAR $\gamma$ upregulation in cholangiocarcinoma contributes to cancer cell growth and metastasis [30]. We previously also reported that RAR is overexpressed in HCC and overexpression of RAR $\gamma$ endows HCC cells with malignancy types [31]. In contrast, RARy has also been reported as a tumor suppression factor that inhibits cancer cells proliferation and invasion. For example, RAR $\gamma$, by regulating the expression of carbohydrate sulfotransferase 10 (CHST10), can suppress melanoma invasion [32]. Loss of RAR $\gamma$, but not RAR $\alpha$, promotes v-Ha-Ras-induced squamous cell carcinoma [33]. Recently, we reported that RARy is downregulated in clinical colorectal cancer tissues, and RAR $\gamma$ acts as a tumor suppressor to regulate colorectal tumorigenesis and metastasis by restricting the Hippo-Yap pathway-mediated oncogenic signaling [34]. Taken together, these results strongly indicated that RAR $\gamma$ plays a pivotal role in cancer development. However, it is unknown whether and how RARy is involved in HCC invasion and metastasis.

In the present study, we investigated the role of RAR $\gamma$ in the invasion and metastasis of HCC. Our in vitro and in vivo studies demonstrate that $\operatorname{RAR} \gamma$, acting through NF-kB-mediated E-cadherin reduction, drives HCC cell invasion and metastasis. In clinical HCC samples, we observed a statistical correlation between elevated RAR $\gamma$ expression and distant metastasis and poor survival. These findings implicate that nuclear receptor RAR $\gamma$ may be used as a new potential target for aggressive HCC therapy.

\section{Methods}

\section{Antibody and regents}

Anti-RAR $\gamma$, anti-E-cadherin and anti-Myc tag antibodies were purchased from Santa Cruz Biotechnology (Santa Cruz, CA, USA). all-trans-RA (ATRA) and anti- $\beta$-actin were purchased from Sigma-Aldrich (St. Louis, MO, USA). Lipofectamine 2000 and TRIZOL reagent were purchased from Invitrogen (Carlsbad, CA, USA) and WesternBright ECL reagents were purchased from Advansta (Menlo Park, CA, USA).

\section{Cell culture}

The QGY-7703, MHCC-97H, SMMC-7721, BEL-7402, SK-HEP-1 and Huh-7 human hepatocellular carcinoma cell lines were purchased from the Cell Bank of the Chinese Academy of Sciences (Shanghai, China). These cells were cultured in DMEM medium containing $10 \%$ fetal bovine serum at $37{ }^{\circ} \mathrm{C}$ in a humidified $5 \% \mathrm{CO} 2$ atmosphere.

\section{Tissue samples and evaluation}

Fifty-six human HCC tissues were obtained from the First Affiliated Hospital of Soochow University (Suzhou, Jiangsu, China) from 2012 to 2013. Expression levels of RAR $\gamma$ and E-cadherin were scored using immunohistochemistry in all tissues. The clinical characteristics of all patients included in this study are listed in Table 1. The correlation of RAR $\gamma$ expression and patients' survival outcomes were illustrated using a $\mathrm{HCC}$ tissue microarray (Outdo Biotech Co., Ltd, Shanghai, China) containing 90 HCC samples with survival time. These samples were collected between 2002 and 2009. The study was approved by Soochow University for Biomedical Research Ethics Committee, and all of the patients provided informed consent. The staining score was evaluated as recently described $[35,36]$.

\section{Generation of stable cell lines}

MHCC-97H cell lines stably expressing RAR $\gamma$-specific shRNA (shRNA/RAR $\gamma$ ) or scrambled shRNA control (shRNA/Control) were constructed using a lentiviral shRNA technique (GeneChem, Shanghai, China). The 
Table 1 Correlation of RAR $\gamma$ expression with patients' clinicopathological variables in 56 cases of HCCC

\begin{tabular}{|c|c|c|c|c|c|}
\hline \multirow[t]{2}{*}{ Characteristics } & \multirow[t]{2}{*}{ All cases $(N=56)$} & \multicolumn{4}{|c|}{ RAR $\gamma$ expression (\%) } \\
\hline & & Low $(n=21)$ & High $(n=35)$ & $x^{2}$ value & $p$ value \\
\hline Gender & & & & 0.221 & 0.639 \\
\hline Male & 47 & 17 & 30 & & \\
\hline Female & 9 & 4 & 5 & & \\
\hline Age (years) & & & & 1.026 & 0.311 \\
\hline$\leq 50$ & 15 & 4 & 11 & & \\
\hline$>50$ & 41 & 17 & 24 & & \\
\hline Tumor size (cm) & & & & 5.265 & 0.022 \\
\hline$\leq 3$ & 8 & 5 & 3 & & \\
\hline$>3$ & 48 & 11 & 37 & & \\
\hline Cirrhosis & & & & 0.076 & 0.783 \\
\hline Negative & 28 & 10 & 18 & & \\
\hline Positive & 28 & 11 & 17 & & \\
\hline HBV infection & & & & 0.327 & 0.567 \\
\hline Negative & & 4 & 9 & & \\
\hline Positive & & 17 & 26 & & \\
\hline Distant metastasis & & & & 8.443 & 0.004 \\
\hline No & 26 & 15 & 11 & & \\
\hline Yes & 30 & 6 & 24 & & \\
\hline TNM stage & & & & 8.310 & 0.004 \\
\hline$|/| \mid$ & 41 & 20 & 21 & & \\
\hline III/IV & 15 & 1 & 14 & & \\
\hline Differentiation & & & & 0.448 & 0.799 \\
\hline Well & 6 & 3 & 3 & & \\
\hline Moderate & 25 & 9 & 16 & & \\
\hline Poor & 25 & 9 & 16 & & \\
\hline
\end{tabular}

detailed protocol has been described recently [8]. The human RARY shRNA target sequences were as follows: shRNA/RAR 1 1\#, 5'-CTCCCTTAATCCGAGAGAT-3'; and shRNA/RAR $\gamma$ 2\#, 5'-CTCAGTTAGAAGAGCTCAT-3'.

\section{Western blot and immunofluorescence stainng}

Western blot was performed as described recently [8]. Protein expression was detected using primary and secondary antibodies, and visualized using enhanced chemiluminescence reagents and autoradiography. Representative blots are shown from three independent experiments. Cells for immunofluorescence staining were grown and stained as previously described [37]. The images were taken with a Nikon ECLIPSE Ni scope with color camera and were processed by NIS-Elements D 4.10.00 software.

\section{RNA extraction and qPCR analysis}

Total RNAs were extracted and reverse transcribed as recently described $[8,38]$. qPCR was undertaken using genespecific primers for E-cadherin with Power SYBR ${ }^{\bullet}$ Green
PCR Master Mix (TaKaRa, Japan). Normalization was performed with $\beta$-actin. The following primers were used: E-cadherin, forward 5'-GTCACTGACACCAACGATAAT CCT-3' and reverse 5'-TTTCAGTGTGGTGATTACGA CGTTA-3'; $\beta$-actin forward 5'-CACCAACTGGGACGAC ATG-3' and reverse 5'-GCACAGCCTGGATAGCAAC-3'.

\section{Transwell migration and Matrigel invasion assays}

For transwell migration assays, $7.5 \times 10^{4}$ MHCC-97H cells in $0.5 \mathrm{ml}$ serum-free DMEM medium were added to the top chamber, and the bottom chamber was filled with $0.5 \mathrm{ml}$ DMEM medium with $10 \%$ FBS. After $24 \mathrm{~h}$, cells located on the upper surface were removed using a cotton swab, and the cells on the lower surface were fixed with $100 \%$ methanol for $5 \mathrm{~min}$, and then stained with Wright-Giemsa at room temperature. For matrigel invasion assays, BD BioCoat Matrigel Invasion Chambers (Catalog No. 354480) were used for the invasion assay according to the instructions of the manufacturer. To quantify the migratory and invasive 
cells microscopically, cells were counted in five random fields (magnification, 200x).

\section{Metastasis of Xenografts}

In this study, $1 \times 10^{6} \mathrm{MHCC}-97 \mathrm{H} / \mathrm{shRNA} /$ Control or MHCC-97H/shRNA/RAR $\gamma$ cells were injected into the lateral vein in the nude mouse tail (BALB/c, SPF grade, 4-5 weeks, male). After 7 weeks, mice of each group were killed. Lung tissues were collected for metastatic foci evaluation and standard histopathological study. All animal experiments were approved by the Animal Care and Use Committee of Soochow University.

\section{Statistical analysis}

Each assay was performed in three independent experiments. Data were presented as mean \pm s.d. Statistical significance was analyzed using Student's $t$-test (unpaired, two-tailed) or one-way ANOVA. The relationships between RAR $\gamma$ expression and clinicopathological factors were analyzed using Pearson's chi-square test, and the correlations between the expression levels of RAR $\gamma$ and E-cadherin were calculated using Spearman's rank Correlation analysis. The Kaplan-Meier survival analysis was used to illustrate the prognostic relevance of RAR $\gamma$ in univariate analysis. $p<0.05$ was considered statistically significant.

\section{Results}

RAR $\gamma$ is elevated in HCC specimens and correlates with distant metastasis and poor survival

To determine the role of RAR $\gamma$ in HCC invasion and metastasis, western blotting was first performed to examine the expression of RARy in human HCC tissues. Compared with the matched surrounding tissues of $\mathrm{HCC}$, an overexpression of RARy was detected in the primary HCC tumors (Fig. 1a). Furthermore, we examined gene expression data from Oncomine, and found that RAR $\gamma$ mRNA levels are significantly upregulated in HCC tissues compared with liver cancer precursor tissues (Fig. 1b). In agreement with these results, by analyzing an additional 56 cases HCC samples, we found that RARy expression is overexpressed in tumor tissues (Fig. 1c and d), and further upregulated in those with lymph node metastasis (LNM) (Fig. 1e and f), suggesting RAR $\gamma$ 's potential role in invasive progression of HCC.

We further analyzed the relationship between the levels of RAR $\gamma$ expression and the clinicopathological status of patients with HCC. As shown in Table 1, patients with higher RAR $\gamma$ expression are significantly associated with larger tumor size, distant metastasis and high TNM stage of HCC. However, there is no significant correlation between $\mathrm{RAR} \gamma$ expression and other clinicopathological features, such as patient gender, age, cirrhosis, HBV infection and differentiation.
We next sought to determine whether RAR $\gamma$ expression in HCC is associated with patient survival time. Kaplan-Meier analysis revealed that patients with high RAR $\gamma$ expression have poorer overall survival. The median survival time of HCC patients with high RARy expression was $<20$ months, while the median survival time was significantly longer ( $\sim 70$ months) in those with low RAR $\gamma$ expression (Fig. 1g). These data suggest that elevated RAR $\gamma$ expression may contribute to HCC progression and its expression may be a valuable predicting factor for survival in HCC patients.

\section{Knockdown of RARy expression inhibits HCC cell migration and invasion in vitro, and metastasis in vivo}

The above findings indicate the involvement of elevated RAR $\gamma$ expression in HCC aggressiveness. Based on these findings, we investigated whether RAR $\gamma$ plays a critical role in regulating $\mathrm{HCC}$ cell invasion and metastasis. We first used a lentiviral-mediated shRNA technique to stably knock down RAR $\gamma$ expression in MHCC-97H cell lines that express a high level of RAR $\gamma$ protein. The knockdown efficiency was confirmed by western blotting (Additional file 1: Figure S1). Migration assays show that knockdown of RAR $\gamma$ largely impairs the ability of HCC cell migration, as compared with control cells (Fig. 2a and b). Similarly, invasion assays also reveal that knockdown of RARY potently inhibits HCC cell invasive properties (Fig. 2c and d). We further examined the effect of RARy on HCC metastasis by establishing mouse model for studying HCC metastasis in vivo. MHCC-97H cells having high metastatic potential were used for the study. Our results show that depletion of RAR $\gamma$ greatly impairs HCC metastasis to the lungs, indicated by the fact that MHCC-97H/shRNA/Control cells form more and larger pulmonary micrometastases than the MHCC-97H/ shRNA/RAR $\gamma$ cells (Fig. 2e). These findings are also summarized in Fig. 2f. Evidently, these results indicate that $\mathrm{RAR} \gamma$ acts to promote the invasive property of $\mathrm{HCC}$ cells in vitro and in vivo.

\section{$\mathrm{RAR} y$ regulates E-cadherin expression}

Given that RARy contributes to HCC invasion and metastasis, we investigated that the effect of RAR $\gamma$ on EMT, a critical event in cancer cell invasion and metastasis. Interestingly, as shown in Fig. 3a, knockdown of RARy in MHCC-97H cells significantly enhanced the expression of E-cadherin, an epithelium marker in EMT. This result was also confirmed by immunofluorescent staining (Fig. 3b). Conversely, overexpression of RAR $\gamma$ in Huh-7 cells that express a low level of RAR $\gamma$ protein markedly decreased E-cadherin expression as revealed by the western blot (Fig. 3c) and immunofluorescent staining (Fig. 3d). However, we did not observe any significant change in expression of other EMT markers 


\section{a}

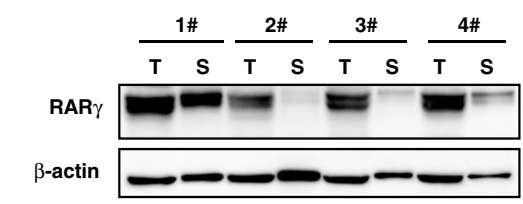

\section{b}

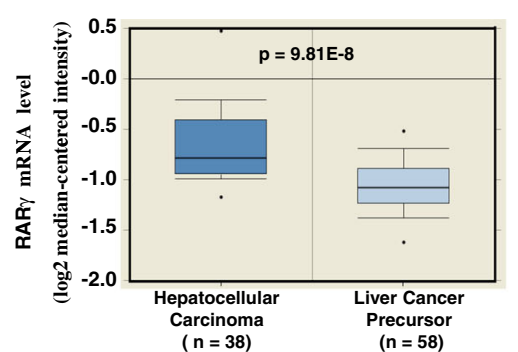

C
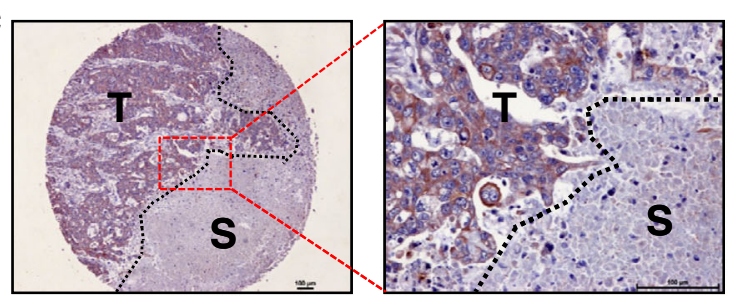

d

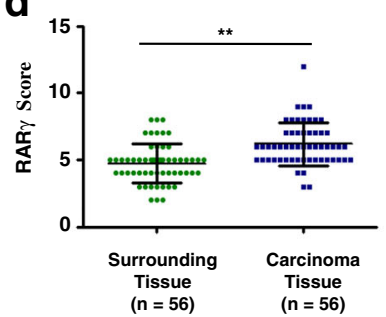

$\mathbf{e}$
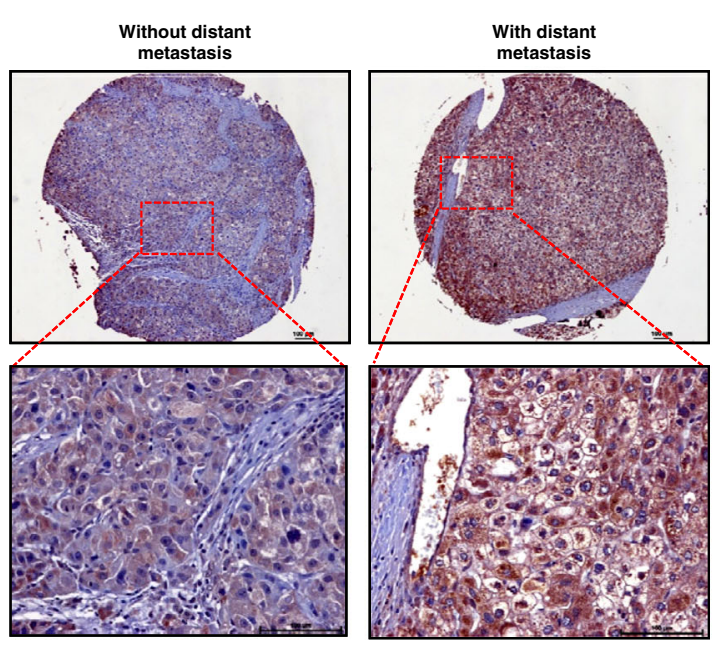

f

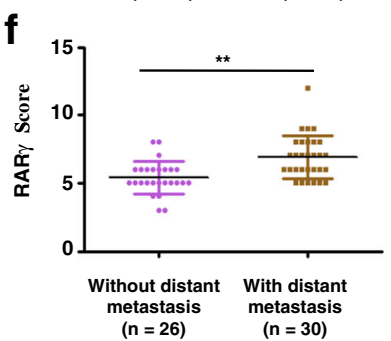

g
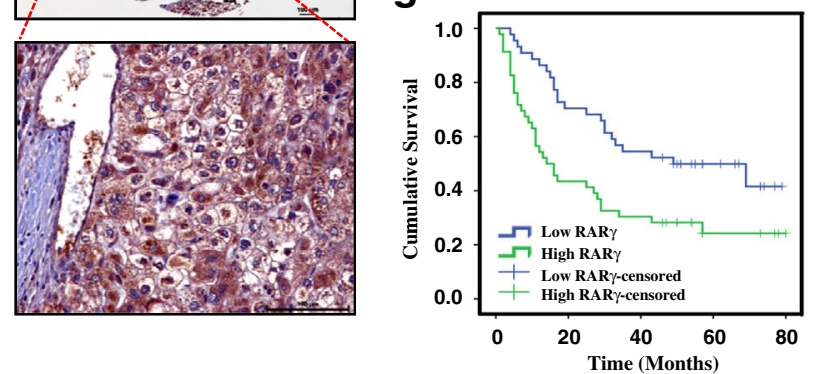

Fig. 1 Increased levels of RARy in HCC correlates with distant metastasis and predicts poor clinical outcome. a RARy expression in HCC samples was evaluated by western blotting. Four randomly selected pairs of HCC tumors (T) and matched surrounding tissues (S) are presented. b Box plot shows the mRNA levels of RARy expression in 38 human HCC and 58 human liver cancer precursor tissues. Statistical significance was determined by a two-tailed, unpaired Student's t-test. c Representative bright-field images showing RARy staining (brown) in human HCC sections. Nuclei (blue) were marked by hematoxylin staining. Scale bar: $100 \mu \mathrm{m}$. T, tumor. S, surrounding tissue. d Scatter plot analysis of RARy levels in 56 HCC tissue samples and their surrounding tissues. Statistical significance was determined by a two-tailed, paired Student's t-test. ${ }^{* *} p<0.01$. e Representative bright-field images showing RARY staining (brown) in human HCC tissues with distant metastasis $(N=30)$ and without distant metastasis $(N=26)$. Nuclei (blue) were marked by hematoxylin staining. Scale bar: $100 \mu \mathrm{m}$. f Scatter plot analysis of RARy levels in human HCC tissues with distant metastasis ( $N=30)$ and without distant metastasis $(N=26)$. Statistical significance was determined by a two-tailed, unpaired Student's t-test. ${ }^{* *} p<0.01$. $\mathbf{g}$ Kaplan-Meier survival curve of HCC patients with low $(n=44)$ and high $(n=46)$ RARy expression

such as Vimentin, N-cadherin and occludin (Additional file 2: Figure S2). We next examined whether ATRA, an agonist for RARs, has an effect on E-cadherin expression. Our results show that treatment of Huh-7 cells with ATRA enhances RAR $\gamma$-induced E-cadherin reduction (Fig. 3e). However, ATRA has no significant effect on the MHCC-97H cells in which RARy is knocked down by siRNA (Fig. 3f), suggesting that RAR $\gamma$ - mediated E-cadherin reduction can be regulated by its ligands.

\section{RARY-induced E-cadherin reduction is dependent on NF-KB Activation}

The next task was to address how RAR $\gamma$ regulates Ecadherin expression. Huh-7 cells were treated with MG132, an inhibitor of protease, and then E-cadherin 
a

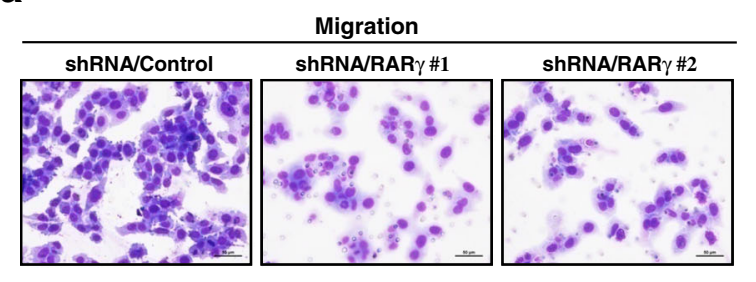

C

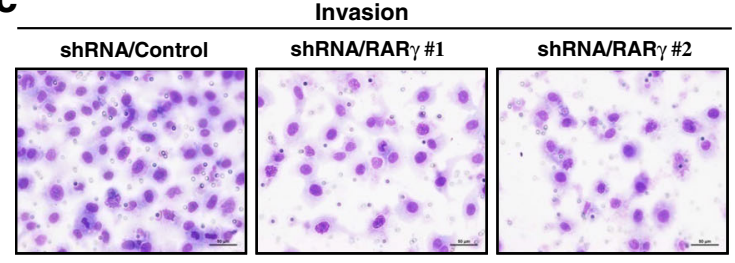

e

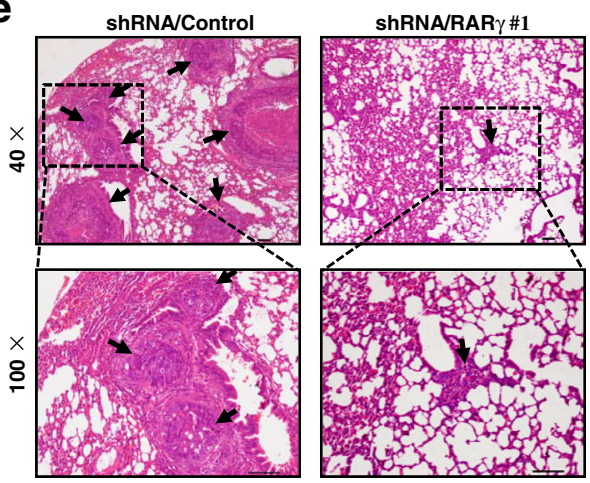

b

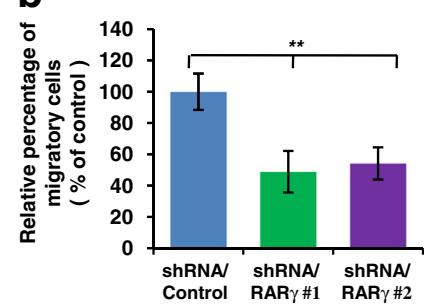

d

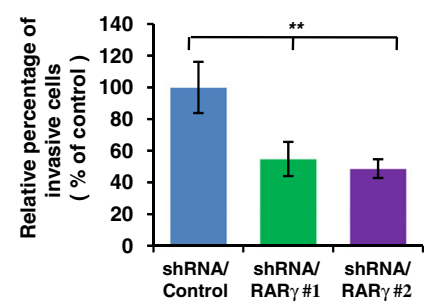

f

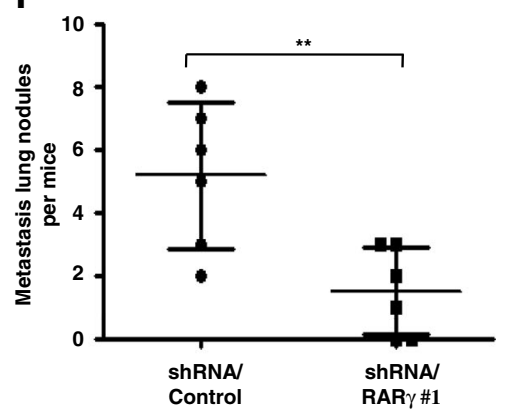

Fig. 2 Silencing RARY impaires HCC migration and invasion in vitro and metastasis in vivo. a-d Migration (a) and invasion (c) assays were performed in wild-type MHCC-97H cells (shRNA/Control) and in the MHCC-97H cells with stable knock down of RARY (shRNA RARy), and the relative number of migratory (b) and invasive (d) cells were calculated with Wright-Giemsa staining. e Knockdown of RARY inhibits HCC metastasis. Representative lung tissue sections from each group were shown by hematoxylin and eosin staining (magnification: $\times 40$ ). Black arrows indicate lung tissues with matastatic nodules. $\mathbf{f}$ The number of lung metastatic foci in each group ( $n=6$ per group) was counted under the microscope. Statistical significance was determined by a two-tailed, unpaired Student's t-test. ${ }^{* *} p<0.01$

protein and mRNA levels were examined. However, RAR $\gamma$-induced E-cadherin reduction at protein and mRNA levels was not affected by MG132 (Fig. 4a), indicating the regulation of E-cadherin expression by RAR $\gamma$ may occur at the transcriptional level. Real-time PCR assays further confirmed that silencing RARy in MHCC97H cells markedly induced E-cadherin mRNA expression (Fig. 4b), while ectopic RARy expression in MHCC-97H cells largely impaired E-cadherin mRNA expression in a dose-dependent manner (Fig. 4c).

Given the fact that RARy, like other nuclear receptors, can act as a transcription factor to regulate expression of its target gene through binding to its DNA response elements $[39,40]$, it is possible that RAR $\gamma$ may bind to the promoter of E-cadherin to regulate its expression. However, after sequence analysis of the region of E-cadherin promoter between $-2000 \mathrm{bp}$ and $-1 \mathrm{bp}$, we did not find a potential RARy binding site within the region (data not shown), suggesting that RAR $\gamma$-driven E-cadherin reduction might be mediated by other molecules or signaling pathways. Interestingly, in the process of exploring which molecular or signaling pathway was involved in RAR $\gamma$ induced E-cadherin reduction, we were surprised to find that BMS-345541, an inhibitor of NF-kB signaling pathway, completely blocked RAR $\gamma$-induced E-cadherin reduction both at mRNA levels (Fig. 4d) and at protein levels (Fig. 4e) in Huh-7 cells. This suggests that the activation of NF-KB signaling is required for RAR $\gamma$-induced Ecadherin reduction. To further confirm this finding, we treated MHCC-97H with tumor necrosis factor $\alpha$ (TNF $\alpha)$, an agonist against the NF- $\mathrm{BB}$ signaling pathway, and found that TNF $\alpha$ significantly enhanced RAR $\gamma$-induced E-cadherin reduction (Fig. 4f) and greatly impaired upregulation of E-cadherin by silencing RARY (Fig. 4g). Together, these results demonstrate that NF- $\mathrm{kB}$ signaling is indispensable for the regulation of E-cadherin by RAR $\gamma$. 


\section{a}

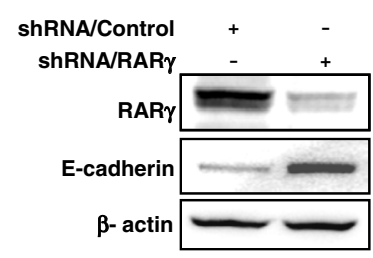

C

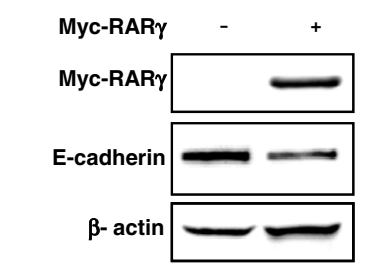

d

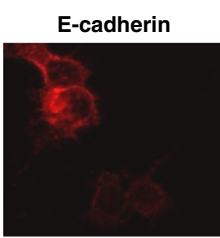

DAPI

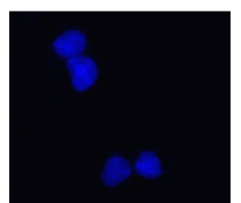

Myc-RAR $\gamma$

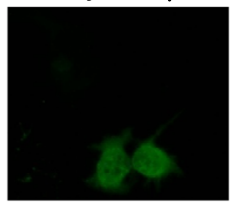

Merge

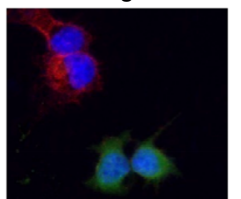

b E-cadherin
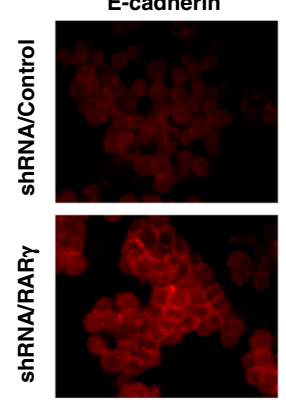

e
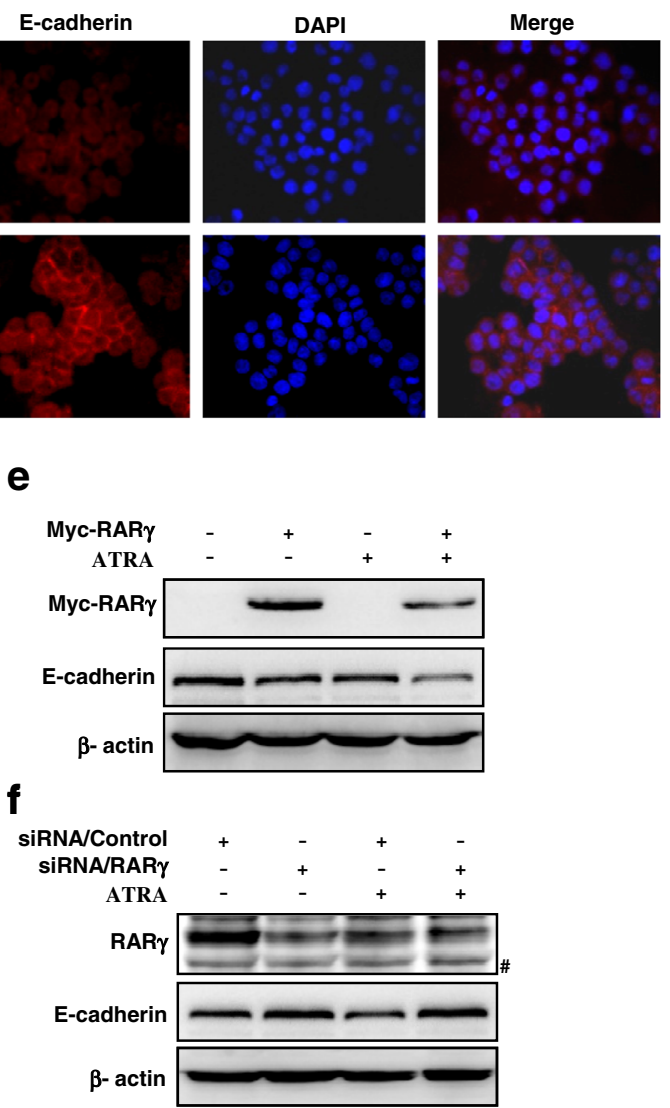

Fig. 3 RARy regulates E-cadherin expression. a, b silencing RARy increases endogenous levels of E-cadherin proteins. MHCC-97H cells stably expressed shRNA/Control or shRNA/RARy, then (a) total cell lysates were subjected to immunoblotting to determine E-cadherin levels, or (b) the cells were subjected to immunofluorescent staining of E-cadherin (red). Nuclei was stained with DAPI (blue). Representative images are shown. c, d RARY overexpression decrease endogenous E-cadherin protein levels. Huh-7 cells were transiently transfected with vector or Myc-tagged RAR $y$, then endogeous protein levels of E-cadherin were detected by immunoblotting (c) or immunofluorescent staining (d). e, $\mathbf{f}$ The role of ATRA in RARY-induced E-cadherin downregulation. Immunoblotting of E-cadherin in RARY-transfected Huh-7 cells (e) or in RARY-silenced MHCC-97H cells (f) treated with vehicle or $1 \mu \mathrm{M}$ ATRA. \#, no specific band

RARY expression is negatively correlated with E-cadherin expression in HCC cell lines and clinical HCC samples

To further examine the RAR $\gamma$-E-cadherin relationship, we analyzed the expression of RAR $\gamma$ and E-cadherin in HCC cell lines and clinical HCC samples. Interestingly, we notice a significant correlation in the expression of RAR $\gamma$ and E-cadherin both at the mRNA (Fig. 5a and b) and protein (Fig. 5c and d) levels in six HCC cell lines. The correlation of RARY and E-cadherin was further validated by examining the expression of these two molecules in 56 cases of HCC tissues using immunohistochemical staining. Our results showed that low RAR $\gamma$ expression was associated with high E-cadherin expression in Case 1 (Fig. 5e). Inversely, the high levels of RAR $\gamma$ correlated with the low levels of E-cadherin in Case 2 (Fig. 5e). Spearman's Rank Correlation analysis confirmed that there is a significant negative correlation between RAR $\gamma$ and E-cadherin expression (Fig. 5f). Thus, these observations further strengthened our finding that RAR $\gamma$ promotes HCC invasion and metastasis through regulation of E-cadherin reduction.

\section{Discussion}

Emerging evidence suggests that aberrant expression of nuclear receptor RAR $\gamma$ contributes to cancer development and progression [30, 31, 34]. In our previous studies, RAR $\gamma$ was identified as an oncogene that was associated with hepatocellular tumorigenesis by activating PI3K/Akt and NF- $\mathrm{KB}$ signaling pathway [31]. An overexpression of RAR $\gamma$ was found in HCC tissues, and its expression was closely correlated with the proliferation and growth of HCC cells [31], indicating its critical 


\section{a}

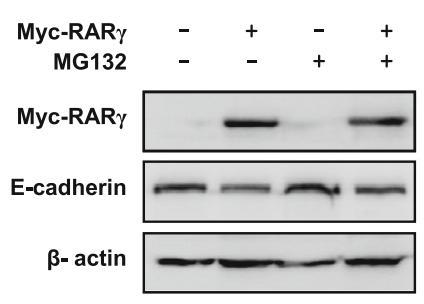

b

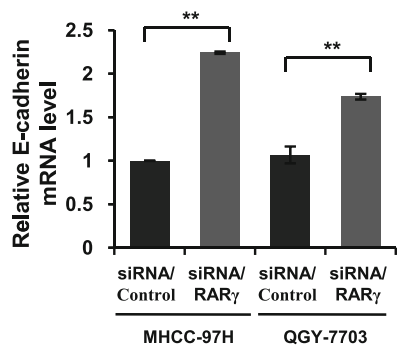

d

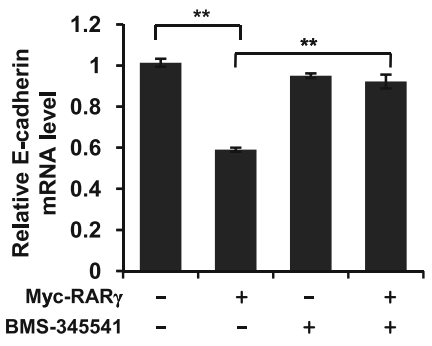

f

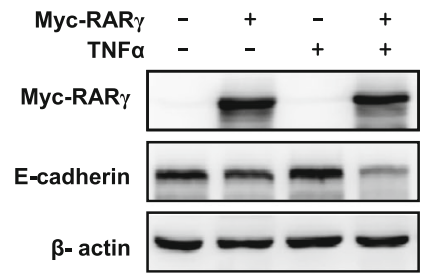

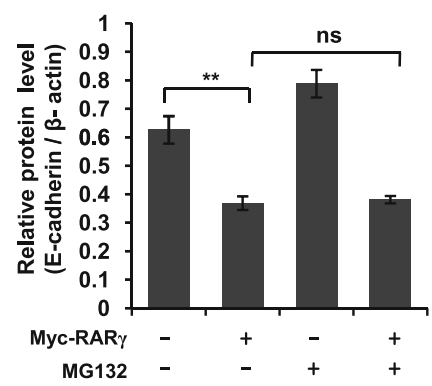

C

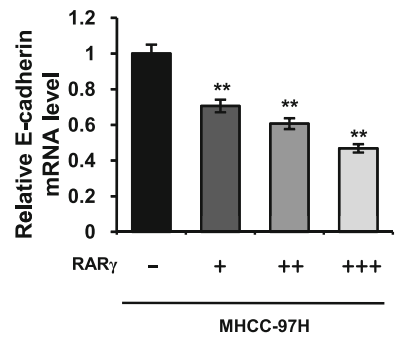

e

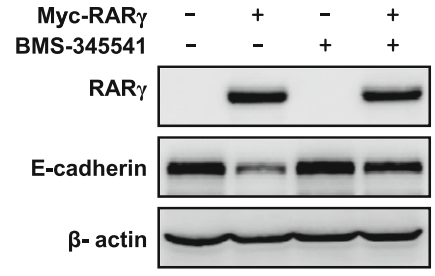

g

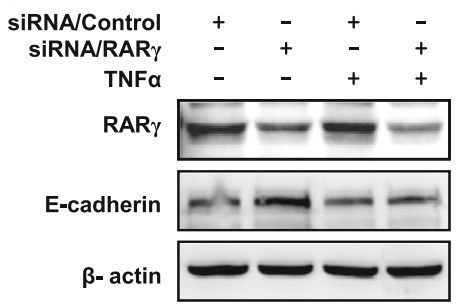

Fig. $4 \mathrm{NF}-\mathrm{KB}$ is indispensable for RARY-driven E-cadherin reduction. a RARY-driven E-cadherin reduction does not depend on proteasome pathway. Immunoblotting (left) or qPCR (right) analysis of the E-cadherin expression in RARy-transfected Huh-7 cells treated with vehicle or $10 \mu \mathrm{M}$ MG132. b, c RARy regulates E-cadherin at transcriptional level. qPCR analysis of the E-cadherin expression in RARy siRNA-transduced MHCC-97H and QGY-7703 cells (b) or RARy-transfected MHCC-97H cells (c). d, e BMS-345541 inhibits RARY-driven E-cadherin reduction. qPCR (d) or immunoblotting (e) analysis of the E-cadherin expression in RARY-transfected Huh-7 cells treated with vehicle or $10 \mu \mathrm{M}$ BMS-345541. $\mathbf{f}, \mathbf{g}$ TNFa promotes RARY-driven E-cadherin reduction. Immunoblotting analysis of the levels of E-cadherin expression in RARy-transfected Huh-7 cells ( $f$ ) or RARy siRNA-transduced MHCC-97H cells (g) treated with vehicle or $20 \mathrm{nM}$ TNFa. Statistical significance was determined by a two-tailed, unpaired Student's $t$-test. ${ }^{* *} p<0.01$. ns, no significance

role in HCC development. However, it remains unclear whether aberrant expression of RARy performs key roles in HCC invasion and metastasis.

In this study, we determined the significance and underlying mechanism for RAR $\gamma$ in HCC invasion and metastasis. The RARy expression was markedly higher in HCC tissues with distant metastasis than in those $\mathrm{HCC}$ tissues without distant metastasis, suggesting a key role of RAR $\gamma$ in HCC progression. Analyzing the relationship between RARY expression and pathological characteristics in $56 \mathrm{HCC}$ patients by tissue microarray revealed a significant correlation of RAR $\gamma$ expression with TNM stages and distant metastasis. Kaplan-Meier analysis further showed that RAR $\gamma$ expression was closely correlated with the overall survival of HCC patients. Thus, these data indicated that RAR $\gamma$ might be 


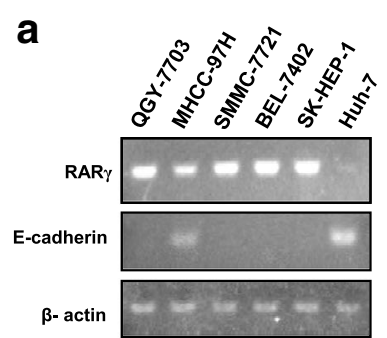

\section{b}

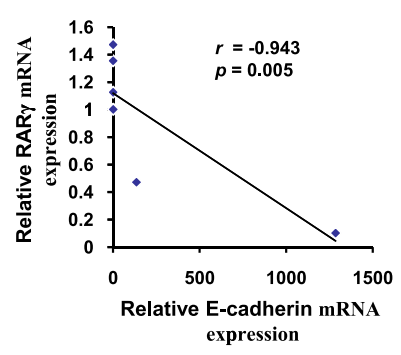

C

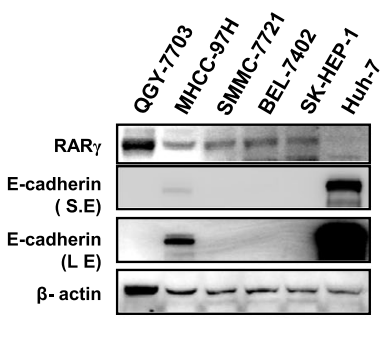

d

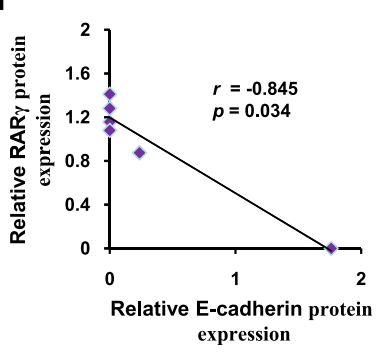

f

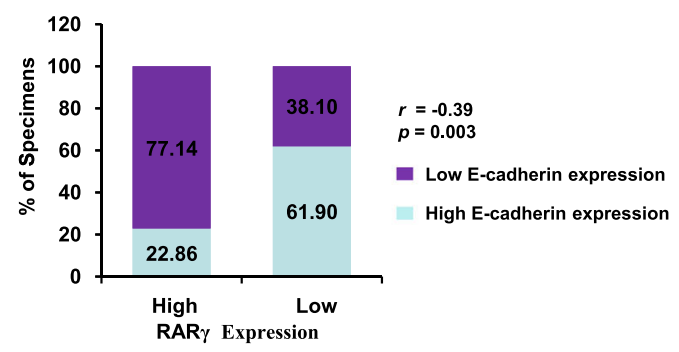

e
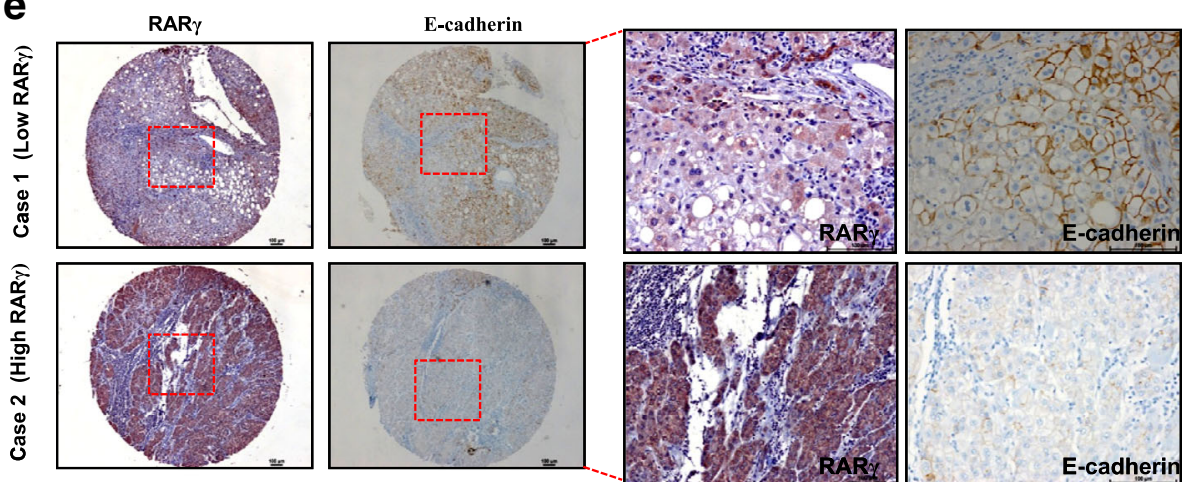

Fig. 5 The expression levels of RARY and E-cadherin in HCC cell lines and clinical HCC tissues. a The expression of RARy and E-cadherin were evaluated by RT-PCR in the indicated cell lines. $\mathbf{b}$ Dot plot correlates the mRNA levels of RARY and E-cadherin in HCC cell lines. The dotted line shows the negative correlation of RARY and E-cadherin at the mRNA levels. $\mathbf{c}$ Immunoblotting analysis of RARY and E-cadherin expression in the indicated cell lines. $\mathbf{d}$ The dot plot correlates RARY and E-cadherin protein levels in six HCC cell lines. The dotted line shows the negative corralation of RARY and E-cadherin at the protein levels. e Immunohistochemical staining of RARY and E-cadherin in human CRC tissues. Representative bright-field images showing RARY and E-cadherin staining in human HCC sections. Scale bar: $100 \mu \mathrm{m}$. f Spearman's correlation analysis between RARy and E-cadherin in 56 cases of HCC tissues

considered a biomarker candidate for clinical HCC prognosis. The effect of RARY on HCC cells invasion and metastasis was directly demonstrated in our in vitro and in vivo studies. Silencing RAR $\gamma$ significantly inhibits the invasive ability of HCC cells, and led to severe suppression of lung metastasis of HCC in mice. These observations are in good agreement with previous reports that high levels of RARY expression in cholangiocarcinoma (CCA) promote CCA cell invasion [30].

Our current study demonstrated that RAR $\gamma$ acts as a metastasis-promoting protein in HCC through regulating NF-kB-dependent E-cadherin reduction. EMT plays a critical role in cancer metastasis. Cancer cells undergoing EMT acquire invasive properties [41]. Accumulating studies have revealed that EMT is a crucial mechanism in cancer progression and metastasis, and many proteins involve in this process [11]. In this study, we found that RAR $\gamma$ is indeed involved in EMT. Modulation of RAR $\gamma$ expression by siRNA or overexpression resulted in a significant change in E-cadherin expression. Loss or reduction of E-cadherin, an epithelium marker, is a hallmark of EMT. Loss or reduction of E-cadherin expression is often associated with the tumor grade and stage [42]. Several molecules and signaling have been identified to regulate E-cadherin expression by transcriptional or post-transcriptional mechanism [21, 25, 43]. We recently reported that upregulation of Nur77, an orphan member of the nuclear receptor superfamily, confers colorectal cancer invasive features through regulating MMP-9dependent E-cadherin reduction [8]. One important 
finding reported here is that we identified inflammatory signaling NF- $\mathrm{KB}$ is involved in RAR $\gamma$-driven EMT. Inhibition of NF- $\mathrm{KB}$ activity by pharmaceutical markedly impaired RAR $\gamma$-induced E-cadherin reduction, while enhancement of NF- $\mathrm{kB}$ activity by inflammatory cytokine TNF $\alpha$ greatly promoted RAR $\gamma$-induced E-cadherin reduction. These results suggest a requirement for inflammatory signaling NF-kB in RAR $\gamma$-driven EMT. It is worthwhile to point out that recent studies revealed that NF-kB-mediated Snail stabilization might trigger inflammation-induced cancer cell migration and invasion [44]. This finding, together with ours, is in agreement with the notion that inflammatory tumor microenvironment facilitates both tumor development and metastatic progression. Indeed, epidemiologic studies have provided overwhelming evidence that chronic inflammation with hepatitis $B$ virus (HBV) or hapatitis $\mathrm{C}$ virus (HCV) infections contributes to HCC development [6, 7], and extensive studies have revealed that genetically or chemically induced HCC depends on inflammatory signaling $[45,46]$. Although we previously reported that RAR $\gamma$-driven inflammatory signaling NF- $\mathrm{kB}$ promotes hepatocellular tumorigenesis [31], whether the mechanism also accounts for HCC invasion and metastasis is unknown. We here demonstrate that a key role of RAR $\gamma$ in induction of HCC metastasis through regulation of NF- $\mathrm{kB}$-mediated Ecadherin downregulation.

\section{Conclusions}

In summary, we have identified RAR $\gamma$ as a key regulator of HCC invasion and metastasis. RAR $\gamma$ upregulation in HCC cells and HCC tissues contributes to their proinvasive and prometastatic abilities in vitro and in vivo by regulating inflammatory signaling NF-kB-mediated Ecadherin reduction. This may highlight a new therapeutic opportunity for intervention of HCC metastasis by blocking RAR $\gamma$-driven EMT.

\section{Additional files}

Additional file 1: Figure S1. The efficiency of RARY depletion in MHCC-97H. Immunoblotting of RARY in MHCC-97H cells that stably transfected with shRNA/Control or shRNA/RARY. (PDF $57 \mathrm{~kb}$ )

Additional file 2: Figure S2. Knockdown of RARy does not affect the expression of Vimentin, $\mathrm{N}$-cadherin and Occludin. qPCR analysis of the vimentin, $\mathrm{N}$-cadherin and occludin expression in RARY siRNA-transduced MHCC-97H cells. Statistical significance was determined by a two-tailed, unpaired Student's t-test. ns, no significance. (PDF $30 \mathrm{~kb}$ )

\section{Abbreviations}

EMT: Epithelial-mesenchymal transition; HCC: Hepatocellular Carcinoma; qPCR: Quantitative PCR

\section{Acknowledgements}

We thank Tingdong Yan (Duke-NUS Graduate Medical School Singapore, Singapore) for critical review of the manuscript and helpful suggestions.

\section{Funding}

This work was supported by National Natural Science Foundation of China (81372574, 31300630, 31540036 to H.W., 81272300, 31570753, 81525020 to J-M.L. and 81401942 to W-J.G), and Natural Science Foundation of Jiangsu Province (BK20130337 to H.W., BE2016666 to J-M.L). This work was also supported by a project funded by the Priority Academic Program Development of Jiangsu Higher Education Institutions.

\section{Availability of data and materials}

Data sharing not applicable to this article as no datasets were generated or analysed during the current study.

\section{Authors' contributions}

HW and JML designed the experiments, analyzed data and prepared the manuscript. WJG, JRW, XLZ, XSH, PDG, SZ and XML performed the experiments. All authors read and approved the final manuscript.

\section{Competing interests}

The authors declare that they have no competing interests.

\section{Consent for publication}

Not applicable.

\section{Ethics approval and consent to participate}

All human HCC subjects signed an informed consent form. The using of tissue samples and nude mouse was approved by the Animal Care and Use Committee of Soochow University.

\section{Author details}

${ }^{1}$ Pathology Center and Department of Pathology, Soochow University, Suzhou 215123, China. ${ }^{2}$ The First Affiliated Hospital of Soochow University, Suzhou 215006, China.

Received: 20 August 2016 Accepted: 8 October 2016

Published online: 19 October 2016

\section{References}

1. He J, Gu D, Wu X, Reynolds K, Duan X, Yao C, Wang J, Chen CS, Chen J, Wildman RP, et al. Major causes of death among men and women in China. N Engl J Med. 2005;353(11):1124-34.

2. Parkin DM, Bray FI, Devesa SS. Cancer burden in the year 2000. The global picture. Eur J Cancer. 2001;37 Suppl 8:S4-66.

3. Yeo W, Mok TS, Zee B, Leung TW, Lai PB, Lau WY, Koh J, Mo FK, Yu SC, Chan AT, et al. A randomized phase III study of doxorubicin versus cisplatin/ interferon alpha-2b/doxorubicin/fluorouracil (PIAF) combination chemotherapy for unresectable hepatocellular carcinoma. J Natl Cancer Inst. 2005;97(20):1532-8.

4. Portolani N, Coniglio A, Ghidoni S, Giovanelli M, Benetti A, Tiberio GA, Giulini SM. Early and late recurrence after liver resection for hepatocellular carcinoma: prognostic and therapeutic implications. Ann Surg. 2006;243(2):229-35.

5. Du ZG, Wei YG, Chen KF, Li B. Risk factors associated with early and late recurrence after curative resection of hepatocellular carcinoma: a single institution's experience with 398 consecutive patients. Hepatobiliary Pancreat Dis Int. 2014;13(2):153-61.

6. Fattovich G, Stroffolini T, Zagni I, Donato F. Hepatocellular carcinoma in cirrhosis: incidence and risk factors. Gastroenterology. 2004;127(5 Suppl 1):S35-50.

7. Aravalli RN, Steer CJ, Cressman EN. Molecular mechanisms of hepatocellular carcinoma. Hepatology. 2008;48(6):2047-63.

8. Wang JR, Gan WJ, Li XM, Zhao YY, Li Y, Lu XX, Li JM, Wu H. Orphan nuclear receptor Nur77 promotes colorectal cancer invasion and metastasis by regulating MMP-9 and E-cadherin. Carcinogenesis. 2014;35(11):2474-84.

9. Zhou ZJ, Dai Z, Zhou SL, Hu ZQ, Chen Q, Zhao YM, Shi YH, Gao Q, Wu WZ, Qiu SJ, et al. HNRNPAB induces epithelial-mesenchymal transition and promotes metastasis of hepatocellular carcinoma by transcriptionally activating SNAIL. Cancer Res. 2014;74(10):2750-62.

10. Spano D, Heck C, De Antonellis P, Christofori G, Zollo M. Molecular networks that regulate cancer metastasis. Semin Cancer Biol. 2012;22(3):234-49.

11. Lamouille S, Xu J, Derynck R. Molecular mechanisms of epithelialmesenchymal transition. Nat Rev Mol Cell Biol. 2014;15(3):178-96. 
12. Perl AK, Wilgenbus $P$, Dahl U, Semb H, Christofori G. A causal role for E-cadherin in the transition from adenoma to carcinoma. Nature. 1998;392(6672):190-3.

13. David JM, Rajasekaran AK. Dishonorable discharge: the oncogenic roles of cleaved E-cadherin fragments. Cancer Res. 2012;72(12):2917-23.

14. Cavallaro U, Christofori G. Cell adhesion and signalling by cadherins and Ig-CAMs in cancer. Nat Rev Cancer. 2004;4(2):118-32.

15. Zhou Y, Li G, Wu J, Zhang Z, Wu Z, Fan P, Hao T, Zhang X, Li M, Zhang F, et al. Clinicopathological significance of E-cadherin, VEGF, and MMPs in gastric cancer. Tumour Biol. 2010;31(6):549-58.

16. Hashiguchi M, Ueno S, Sakoda M, lino S, Hiwatashi K, Minami K, Ando K, Mataki Y, Maemura K, Shinchi H, et al. Clinical implication of ZEB-1 and E-cadherin expression in hepatocellular carcinoma (HCC). BMC Cancer. 2013;13:572.

17. Brooks-Wilson AR, Kaurah P, Suriano G, Leach S, Senz J, Grehan N, Butterfield YS, Jeyes J, Schinas J, Bacani J, et al. Germline E-cadherin mutations in hereditary diffuse gastric cancer: assessment of 42 new families and review of genetic screening criteria. J Med Genet. 2004;41(7):508-17.

18. More H, Humar B, Weber W, Ward R, Christian A, Lintott C, Graziano F, Ruzzo AM, Acosta $E$, Boman $B$, et al. Identification of seven novel germline mutations in the human E-cadherin (CDH1) gene. Hum Mutat. 2007;28(2):203.

19. Berx G, Becker KF, Hofler H, van Roy F. Mutations of the human E-cadherin (CDH1) gene. Hum Mutat. 1998;12(4):226-37.

20. Reinhold WC, Reimers MA, Maunakea AK, Kim S, Lababidi S, Scherf U, Shankavaram UT, Ziegler MS, Stewart C, Kouros-Mehr H, et al. Detailed DNA methylation profiles of the E-cadherin promoter in the $\mathrm{NCl}-60$ cancer cells. Mol Cancer Ther. 2007;6(2):391-403.

21. Cano A, Perez-Moreno MA, Rodrigo I, Locascio A, Blanco MJ, del Barrio MG, Portillo F, Nieto MA. The transcription factor snail controls epithelial-mesenchymal transitions by repressing E-cadherin expression. Nat Cell Biol. 2000;2(2):76-83.

22. Vesuna F, van Diest $P$, Chen $\mathrm{JH}$, Raman V. Twist is a transcriptional repressor of E-cadherin gene expression in breast cancer. Biochem Biophys Res Commun. 2008;367(2):235-41.

23. Bolos V, Peinado H, Perez-Moreno MA, Fraga MF, Esteller M, Cano A. The transcription factor Slug represses E-cadherin expression and induces epithelial to mesenchymal transitions: a comparison with Snail and E47 repressors. J Cell Sci. 2003;116(Pt 3):499-511.

24. Sanchez-Tillo E, Lazaro A, Torrent R, Cuatrecasas M, Vaquero EC, Castells A, Engel $P$, Postigo A. ZEB1 represses E-cadherin and induces an EMT by recruiting the SWI/SNF chromatin-remodeling protein BRG1. Oncogene. 2010;29(24):3490-500.

25. Eger A, Aigner K, Sonderegger S, Dampier B, Oehler S, Schreiber M, Berx G, Cano A, Beug H, Foisner R. DeltaEF1 is a transcriptional repressor of E-cadherin and regulates epithelial plasticity in breast cancer cells. Oncogene. 2005;24(14):2375-85.

26. Comijn J, Berx G, Vermassen P, Verschueren K, van Grunsven L, Bruyneel E, Mareel M, Huylebroeck D, van Roy F. The two-handed E box binding zinc finger protein SIP1 downregulates E-cadherin and induces invasion. Mol Cell. 2001;7(6):1267-78.

27. Machado JC, Oliveira C, Carvalho R, Soares P, Berx G, Caldas C, Seruca R, Carneiro F, Sobrinho-Simoes M. E-cadherin gene (CDH1) promoter methylation as the second hit in sporadic diffuse gastric carcinoma. Oncogene. 2001:20(12):1525-8.

28. Berx G, Cleton-Jansen AM, Nollet F, de Leeuw WJ, van de Vijver M, Cornelisse C, van Roy F. E-cadherin is a tumour/invasion suppressor gene mutated in human lobular breast cancers. EMBO J. 1995;14(24):6107-15.

29. Hajra KM, Chen DY, Fearon ER. The SLUG zinc-finger protein represses E-cadherin in breast cancer. Cancer Res. 2002;62(6):1613-8.

30. Huang GL, Luo Q, Rui G, Zhang W, Zhang QY, Chen QX, Shen DY. Oncogenic activity of retinoic acid receptor gamma is exhibited through activation of the Akt/NF-kappaB and Wnt/beta-catenin pathways in cholangiocarcinoma. Mol Cell Biol. 2013;33(17):3416-3425.

31. Yan TD, Wu H, Zhang HP, Lu N, Ye P, Yu FH, Zhou H, Li WG, Cao X, Lin YY, et al. Oncogenic potential of retinoic acid receptor-gamma in hepatocellular carcinoma. Cancer Res. 2010;70(6):2285-95.

32. Zhao X, Graves C, Ames SJ, Fisher DE, Spanjaard RA. Mechanism of regulation and suppression of melanoma invasiveness by novel retinoic acid receptor-gamma target gene carbohydrate sulfotransferase 10. Cancer Res. 2009;69(12):5218-25.

33. Chen CF, Goyette P, Lohnes D. RARgamma acts as a tumor suppressor in mouse keratinocytes. Oncogene. 2004;23(31):5350-9.
34. Guo PD, Lu XX, Gan WJ, Li XM, He XS, Zhang S, Ji QH, Zhou F, Cao Y, Wang JR, et al. RARgamma downregulation contributes to colorectal tumorigenesis and metastasis by derepressing the hippo-Yap pathway. Cancer Res. 2016:76(13):3813-25.

35. Xing C, Lu XX, Guo PD, Shen T, Zhang S, He XS, Gan WJ, Li XM, Wang JR, Zhao $Y Y$, et al. Ubiquitin-specific protease 4-mediated deubiquitination and stabilization of PRL-3 is required for potentiating colorectal oncogenesis. Cancer Res. 2016;76(1):83-95.

36. Wu H, Li XM, Wang JR, Gan WJ, Jiang FQ, Liu Y, Zhang XD, He XS, Zhao YY, Lu XX, et al. NUR77 exerts a protective effect against inflammatory bowel disease by negatively regulating the TRAF6/TLR-IL-1R signalling axis. J Pathol. 2016;238(3):457-69.

37. Han YH, Zhou H, Kim JH, Yan TD, Lee KH, Wu H, Lin F, Lu N, Liu J, Zeng JZ, et al. A unique cytoplasmic localization of retinoic acid receptor-gamma and its regulations. J Biol Chem. 2009:284(27):18503-14.

38. Li XM, Lu XX, Xu Q, Wang JR, Zhang S, Guo PD, Li JM, Wu H. Nur77 deficiency leads to systemic inflammation in elderly mice. J Inflamm (Lond). 2015;12:40.

39. Kastner P, Mark M, Chambon P. Nonsteroid nuclear receptors: what are genetic studies telling us about their role in real life? Cell. 1995;83(6):859-69.

40. Germain P, Chambon P, Eichele G, Evans RM, Lazar MA, Leid M, De Lera AR, Lotan R, Mangelsdorf DJ, Gronemeyer H. International Union of Pharmacology. LXIII Retinoid X receptors Pharmacol Rev. 2006;58(4):760-72.

41. Iwatsuki M, Mimori K, Yokobori T, Ishi H, Beppu T, Nakamori S, Baba H, Mori M. Epithelial-mesenchymal transition in cancer development and its clinical significance. Cancer Sci. 2010;101(2):293-9.

42. Cowin P, Rowlands TM, Hatsell SJ. Cadherins and catenins in breast cancer. Curr Opin Cell Biol. 2005;17(5):499-508.

43. Wu WJ, Hirsch DS. Mechanism of E-cadherin lysosomal degradation. Nat Rev Cancer. 2009;9(2):143. author reply 143.

44. Wu Y, Deng J, Rychahou PG, Qiu S, Evers BM, Zhou BP. Stabilization of snail by NF-kappaB is required for inflammation-induced cell migration and invasion. Cancer Cell. 2009:15(5):416-28.

45. Sakurai T, Maeda S, Chang L, Karin M. Loss of hepatic NF-kappa B activity enhances chemical hepatocarcinogenesis through sustained c-Jun N-terminal kinase 1 activation. Proc Natl Acad Sci U S A. 2006;103(28):10544-51.

46. Maeda S, Kamata H, Luo JL, Leffert H, Karin M. IKKbeta couples hepatocyte death to cytokine-driven compensatory proliferation that promotes chemical hepatocarcinogenesis. Cell. 2005:121(7):977-90.

\section{Submit your next manuscript to BioMed Central and we will help you at every step:}

- We accept pre-submission inquiries

- Our selector tool helps you to find the most relevant journal

- We provide round the clock customer support

- Convenient online submission

- Thorough peer review

- Inclusion in PubMed and all major indexing services

- Maximum visibility for your research

Submit your manuscript at www.biomedcentral.com/submit
) Biomed Central 